\title{
At Home in the Restaurant: Familiarity, Belonging and Material Culture in Ecuadorian Restaurants in Madrid
}

\author{
University of Trento, Italy

\section{Paolo Boccagni} \\ University of Trento, Italy
}

Alejandro Miranda-Nieto

\begin{abstract}
Making and consuming food are evident aspects in migrants' construction and reproduction of memory, identity and belonging. Food consumption can also enable migrants to make themselves at home abroad by reproducing aspects of their past and relating them to particular places in the present. This article draws from ethnographic work in Ecuadorian restaurants in Madrid to investigate the 'domestication' of space through their material culture. It examines the representation and use of these restaurants to unveil multiple ways of displaying belonging and reproducing degrees of domesticity. Enacting private routines, embodying familiarity through food and decorating backbars are instances that reveal how the material arrangements in migrant-run restaurants facilitate the construction of a sense of home. From a sociological perspective, this article reveals how the boundaries between private and public, as well as migrants' ethnicity and belonging, are constantly reshaped through material arrangements that operate as forms of domestication of space.
\end{abstract}

\section{Keywords}

domestication, Ecuadorians, migrant-origin restaurants, familiarity, food, homemaking, immigration, Madrid, material culture

\section{Introduction}

Are private dwellings the only places where people, and particularly international migrants, can make themselves at home? Probably not, as an increasing body of literature suggests. Semi-public spaces, among them restaurants, may also be a source of domesticity in ways that call for better analysis and research. Following this insight, this

\section{Corresponding author:}

Alejandro Miranda-Nieto, Department of Sociology and Social Research, University of Trento, Via Verdi 26, $38 I 22$, Italy.

Email: alejandro.miranda@unitn.it 
article investigates Ecuadorian restaurants in Madrid as a critical setting for migrants to negotiate a sense of home and familiarity, under the influence of particular material cultures. Food consumption and production are some of the most evident channels through which people construct and negotiate their collective identifications in everyday life (Warde et al., 1999). Besides being at the core of migrant livelihoods, food and its related practices have much to say about the ways in which migrants represent themselves, as individuals and social groups. Over time, food also becomes inherent to patterns of integration, as well as to broader changes in culinary traditions (Abbots, 2016; Bailey, 2017). Because of its deep sensorial dimensions, food elicits significant emotions and memories from the past, mediated by aromas, tastes and ways of eating (Sutton, 2001; Warin and Dennis, 2005). Under circumstances of large-scale migration, these sensorial and emotional experiences may be conducive to the reproduction of a sense of home and familiarity (Sammells, 2016) facilitated within 'spatial niches' such as those provided by migrant-origin restaurants.

In fact, there is far more to food than what is on our plates. The material settings in which familiar foods are consumed have an evocative, emotional and performative power - one that is used by some restaurants to attract their clientele. The material culture of restaurants is a suitable backdrop for research on broader questions of migrant alignment to, and reproduction of, key aspects of what used to be home for them. Besides enabling the recreation of a sense of home through the consumption of more or less 'traditional' or 'typical' food, migrant-origin restaurants make for a semi-public environment that combines the continuity of culinary practices with a variety of influences from the receiving (and indeed, the global) society.

This article examines the material arrangements in a number of restaurants run by immigrants in Madrid. We specifically analyse the representation and use of these materials to understand how familiarity and a sense of home are negotiated and co-produced in a semi-public space. We focus on how these restaurants become 'Ecuadorian', 'Latin American' or simply foreign by people's ways of using and representing material cultures. These restaurants portray national elements in multiple ways. While evoking Ecuador in very visible and often stereotypical forms, Ecuadorian restaurants in Madrid have been peripheral to academic research on migrants themselves - unless, pragmatically, as entry points to seek out research informants. This may not come as a surprise, for a Latin American immigrant minority with high rates of naturalisation is nowadays far less contentious (i.e. publicly visible) than in the past (Córdoba, 2015; Iglesias et al., 2015).

While migrant-origin restaurants evoke immigrant past tastes, lifestyle or rituals, they do so in the terms of the receiving institutional context. The latter sets the rules of the game for them to operate through relevant regulations and the infrastructures available. This circumstance hardly affects, however, their significance as socio-material settings imbued with different ways of constructing migrant collective identities. The material arrangements inside them may reveal a variety of domestic, private, even biographical facets worth investigating further. This article contributes to debates on the social experience of home by building on recent studies of homemaking in the public (Blunt and Sheringham, 2019; Boccagni and Duyvendak, 2019) and the domestication of public space (Koch and Latham, 2013). Research on homemaking and domestication in public 
sites emphasises how a sense of home can be cultivated in and outside the domestic environment. In this article we draw on these debates to argue that under certain circumstances, the private and the public 'drip' onto one another in migrant-origin restaurants, eliciting a sense of home for their owners, workers and clients.

Home is here understood, sociologically, as a relational and context-dependent process whereby social actors try to attach a sense of security, familiarity and control over certain settings (Boccagni, 2017; Kusenbach and Paulsen, 2013). For sociologists, home matters less as a place in itself than as a set of relationships that people negotiate under particular conditions - such as the representation and uses of material settings that we analyse in this article. People's ways of homemaking are relevant to the (semi-)public space because they reveal their socially stratified possibility to appropriate, domesticate or exert meaningful forms of attachment and belonging (Easthope, 2004; HondagneuSotelo, 2017). Studying homemaking in the public, therefore, contributes to at least three sociological research lines: it uncovers social actors' potential and inclinations to attach a sense of home to certain extra-domestic infrastructures; it interrogates the micro, meso and macro social variables that shape these processes over time and space; and it provides a novel research perspective into long-debated questions such as the boundarymaking between the public and the private, or the selective reproduction of ethnicity in post-migration societies.

In what follows, we first give an overview of the literature on the pervasive significance of food in the everyday lives of immigrants. Among other aspects, food consumption can contribute to recreate a sense of home in a dual sense: as continuity and elicitation of pre-migration life patterns and meaningful memories associated with the country of origin, as well as the production of familiarity and intimacy in the present. After describing our case study and research design in the first two sections of this article, we address in section three the ways through which representing the material culture in Ecuadorian restaurants produces a sense of home. We examine how the owners and workers in these restaurants translate meanings of Ecuadorianness through material arrangements. The fourth section looks at specific instances of domestication that emerge from the use of these material settings by analysing how these restaurants become a site for family life, how drawing familiarity from specific dishes requires a set of bodily dispositions, and how the backbar (the space behind the countertop) becomes a niche in which the domestic 'drips' onto the semi-public. We end with a short discussion on the key implications of our study, along with the issues that call for further empirical research. Overall, the significance of investigating the social lives of migrant-origin restaurants rests on showing how people make themselves at home in migratory contexts by reshaping the boundaries between private and public life. This form of emplacement (Wessendorf and Phillimore, 2018) operates as a domestication of space.

\section{Migration, Food and the Domestication of Public Space}

It is probably a truism to say that food evokes a sense of home for many immigrant newcomers, or even for long-settled minorities and their descendants. Yet, it is hard to underestimate its evocative power, since food and memory are intimately associated with issues of identity (Johnson, 2016; Sutton, 2001). Eating what subjectively feels 
like a proper meal has profound sensorial dimensions that facilitate the connection with - and literally, the incorporation of - food associated with comfort and the continuity with previous experiences. As Abbots (2016: 3) highlights, food and its related practices transcend space and time because they 'can effectively transport migrants back "home". Our contention is that the practices involved in the preparation, consumption and commercialisation of food do not just facilitate connections with what used to be home in the past. They also make it possible to domesticate space - in ways that produce a sense of home, as familiarity, intimacy and control (Boccagni, 2017) in the present. For sure, this form of domestication has also to do with the space and material cultures it relies upon. Restaurants, as we argue in this article, are an intriguing case in point.

There is a significant amount of research on so-called 'ethnic' restaurants, especially as forms of migrant entrepreneurship (e.g. Beriss and Sutton, 2007; Krogstad, 2004; Pieterse, 2003; Warde, 2000). While a thorough literature review goes beyond the scope of this article, it is remarkable that most of it associates these restaurants with a common national or cultural foreign tradition. Still, the adjective 'ethnic' and its uses in scholarly analysis are not without problems. In fact, 'ethnic' points less to an essence than to an identity claim that needs to be deconstructed in light of the functions it plays, through different material arrangements and towards a more or less diverse target of (mostly immigrant) clients. As we realised through our fieldwork, the 'ethnic card' can be played in different ways, and be informed by remarkably different views of ethnicity or national belonging. Rather than presuming the existence of an inherently ethnic quality, we tried to understand how different ways of evoking, claiming, enacting and displaying meanings associated with Ecuador - what we call 'Ecuadorianness' - are translated in the restaurant settings. In this article, therefore, we use the term 'migrant-origin restaurants' to focus on material culture as practised, seeking to transition from a static view of symbolic nationality or ethnicity to the evolving ways of constructing a familiar environment for the clients and, possibly, for the workers themselves.

More specifically, we focus on how the material settings in these spaces facilitate the recollection of memories (Mata-Codesal, 2010; Sabar and Posner, 2013), the reproduction of physically remote cultural settings (Zambonelli, 2013) and the construction of a sense of familiarity and home (Abbots, 2016; Blunt and Dowling, 2007; Boccagni, 2017; Collins, 2008). As we show, people's interaction with such material arrangements unveils the social dynamics through which public space becomes domesticated. This analysis follows an insight from Kumar and Makarova (2008), who illustrate how certain activities largely identified as inherent to the privacy of home are actually enacted also in public spaces. Intimate ways of talking and expressing oneself, certain forms of entertainment and eating constitute activities increasingly performed in public that carry traces of their private character. Domesticating public space constitutes a form of individualisation (Kumar and Makarova, 2008: 328), a way of practising the personal and intimate in the public space. As Koch and Latham (2013: 14-15) remark, the spatial imaginary of 'home' can help us to rethink the domestication of public space, here understood as the 'cultivation of a whole range of intimate relationships between humans and other forms of life, artifacts and environments' (2013: 13). These intimate relationships, we argue, constitute forms of domestication in the case of the Ecuadorian restaurants we 
analyse, an instance in which the material translates dimensions of domesticity and foreignness, and privacy and publicness.

\section{Research Context and Methodology}

We base our argument on the ethnographic work we conducted in Ecuadorian restaurants in Madrid, a city that has been at the core of Ecuadorian 'new migration' to Europe in the late 1990s and nowadays hosts a substantive minority of Ecuadorians and Ecuador born. Ecuadorian migration to Madrid has a relatively recent history. Although historically connected, Ecuador and Spain became entangled in an extended migratory system only since the last decades of the 20th century (Herrera and Torres, 2005). There are approximately 87,500 Ecuadorians currently living in Madrid, including people of Ecuadorian descent. The availability of Ecuadorian restaurants responds to the dimension of this migratory system, as well as the distinct culinary practices in Madrid. According to the local census of the council of Madrid, the city has more than 15,000 restaurants, bars and cafes (Ayuntamiento de Madrid, 2018). The offer is wide and there is a culture of eating and drinking out. Making life in the public space is totally common, much more than in many other European cities. Madrid therefore offers excellent opportunities for observing and participating in the ways in which the consumption, commodification and production of food are experienced in public and semi-public spaces.

This article is based on HOMInG, a larger research project in which the authors have collaborated for two years. Focusing on several European cities, we have developed ethnographic analyses on how homemaking and migration become intertwined within and beyond dwelling places. Food has emerged as a significant entry point to the analysis of migration and home, particularly in its material and sensorial dimensions. In addressing these themes, Alejandro Miranda-Nieto conducted participant observation and ethnographic interviews in Madrid from January to June 2018. The production of a sense of home and familiarity at restaurants became a relevant topic that, as a consequence, we decided to further investigate together. On three separate occasions, Alejandro and Paolo Boccagni conducted participant observation in more focused visits, concentrating on restaurants in selected neighbourhoods in three different districts of Madrid: south, in Latina, Carabanchel and Usera; north-east, in Ciudad Lineal; and north, in Tetuán. It is no coincidence that these districts are among those with higher rates of Ecuadorian born residents in Madrid (see the database referred to in note 1). Indeed, most of the restaurants we encountered had co-nationals, or at most Latin Americans, as their main client target. We covered 20 Ecuadorian restaurants overall. We also conducted fieldwork in mainstream Spanish and other migrant-origin restaurants, bars and cafes (such as Peruvian and Chinese) in the aforementioned districts. Our main focus here is on restaurants that call themselves Ecuadorian, as their sign-boards and online sources show. Nonetheless, we argue that migrant-origin restaurants in Madrid - and probably in other cities - cannot be understood as self-contained phenomena. Their meanings, and even their ways of operating, are produced in relational ways, unfolding as part of an 'ecology' of local businesses. In the case of Madrid, there is a historical background of internal migration (Recaño, 2004a, 2004b, 2006) that is closely associated with the emergence of cafes, bars and restaurants in the city. With the increase of international immigration 
in Spain, this 'ecology' has greatly diversified (Cebrián de Miguel et al., 2016), from which 'Ecuadorian' restaurants constitute significant cases.

To an extent, the collaborative fieldwork we conducted can be framed as conventional participant observation: we both spent time, often simultaneously, in selected locales seeking to understand how people's lifeworlds come into being (Jackson, 2017). We got access to these restaurants as ordinary customers, playing a somehow 'covert' role. We then conducted interviews and engaged in casual conversation with the owners whenever they were available and willing to talk. In the latter cases (about half of our ethnographic encounters) our identity would shift into an 'overt' role without affecting our informants' reactions in any visible way. All our interactions were in Spanish. When the two of us were conducting interviews, one of us tended to take the lead of the conversation while the other posed occasional questions or remarks. We alternated between these roles. Fieldnotes, drawings, photos and audio recorded interviews constitute our empirical materials. Importantly, by conducting fieldwork at the same time, in the same places, we were able to test our interpretations in 'real-time' - on the spot and during debriefing sessions. In this sense, the effect of this simultaneous fieldwork was not merely additive. While conducting fieldwork we also got a sense of consumers' practices, but this aspect is out of the reach of this article. This research is, therefore, to be complemented with future analyses on aspects such as the engagement and (mis)alignment towards different forms of Ecuadorianness from the perspective of the clientele.

\section{Co-producing Familiarity in the Restaurant: On the Ways of Representing and Materialising 'Ecuador'}

Among the multitude of places to eat and drink in Madrid, there is a considerable number of restaurants that label themselves as Ecuadorian. Relatively small in size, offering affordable and hearty menus, these places evoke Ecuador in conspicuous and often stereotypical ways, as is probably the case of most migrant-origin restaurants. In investigating how migrants' collective belonging is evoked, and how a restaurant claims, displays and uses such a notion, our fieldwork suggests four ways of representing Ecuadorianness and domesticating the semi-public space: identitarian; liminal; touristic; and distinctive. These are ideal types, an analytical product of our own categorisation that seeks to unveil the strategies used in these restaurants.

\section{Identitarian: Ecuador as an Essence}

A common way of claiming Ecuadorianness is through what we call the identitarian tactic. This is typical of those restaurants that put strong emphasis on the emblems and commonsensical atmospheres of Ecuador - most notably, through national symbols such as the flag, the shield, the Andean condor or even textual fragments of the national anthem. An example comes from a restaurant in the east of the city (Figure 1). Its facade features the three colours of the Ecuadorian flag topped by a smaller board advertising a local beer. Its windows are small and securitised with bars. The half open door makes it ambiguous if the place is open for business or closed. Inside, fluorescent lights illuminate the entire area, even on a sunny day. As in the case of a Bolivian restaurant that 


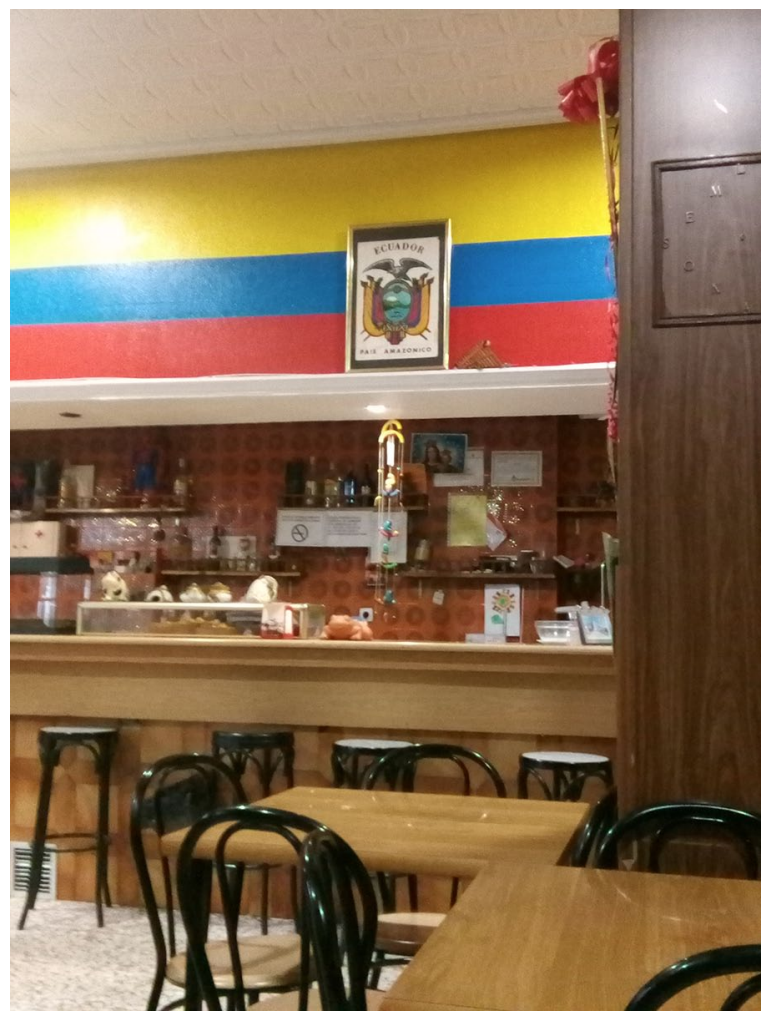

Figure I. Identitarian restaurant.

Sammells (2016) observes, curtains and frosted windows are common in Madrid's restaurants as a way of keeping the privacy of the customers from outsiders' eyes. A large bar dominates one side of the place, much like many other mainstream Spanish bar-restaurants; on the other side there are eight tables of different sizes with tablecloths covered with plastic. Dominating the top of the bar, a frame depicting the national shield reproduces the motto 'Ecuador, país amazónico' (Ecuador, Amazonic country). The daily menu and dishes a la carte are typically Ecuadorian and are presented in a way that assumes the clientele knows exactly what is in each dish.

Much of the decoration and arrangement of objects in this place affirms a clear national membership. Still, from a forgotten corner that no one looks at, the TV projects American series, while the backbar features among its bottles large action figures of Spiderman nearby a small frame with the image of a Catholic virgin. As we will illustrate later, the backbar is a corner where the private and personal are brought to the semipublic areas of the restaurant. For now, it suffices to say that the identitarian strategy portrays a reified notion of Ecuadorianness while producing nuance in the materiality of its decorated corners. Located in minor streets away from the main avenues, this and other restaurants cater mostly to a clientele living nearby. 'Why do people come back 


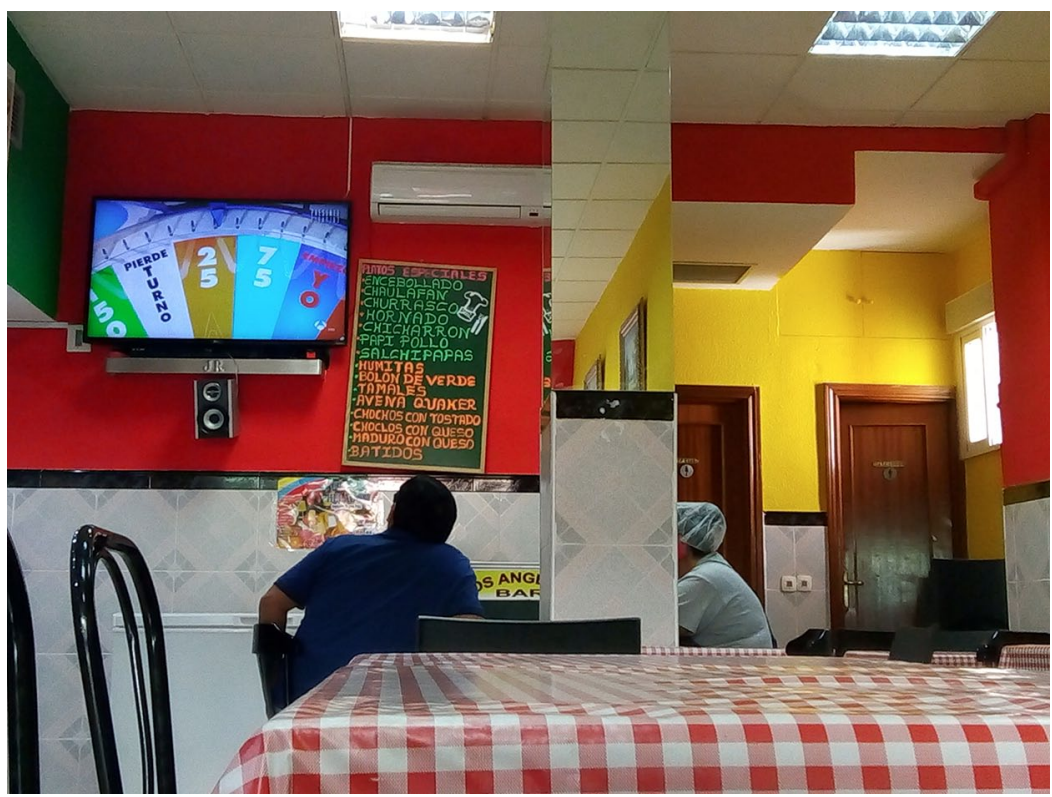

Figure 2. Liminal restaurant.

here to eat?' Paolo asked the owner of an identitarian restaurant. 'Because they like the food', he first replied, but after a moment of reflection he concluded: 'they come to remember'. These restaurants seem to embody a claim for recognition of a country and membership to it, directed towards an arena of clients expected to appreciate this nationalistic ambience no less than the food in itself. Asserting an enduring national or patriotic identity through food is central to them. Assertion that they use as a marketing device.

\section{Liminal: Ecuador as a Background}

Another way of displaying Ecuadorianness is what we call the liminal strategy. This category refers to those restaurants in which the 'typicality' of Ecuador as a nation is less emphasised. A distinctive Ecuadorian cuisine is still visible in the everyday dishes and in much of the clientele, although there is room for a more diverse menu. Served without making any explicit remarks about their belonging, encebollado, menestras, caldo de bola, bandera and other typical Ecuadorian dishes are served beside pollo asado or churrasco, which are also common elsewhere in Latin America. And while the dishes served furnish these restaurants with a form of flexible identity, the material arrangements express a form of ambiguity that seems instrumental for capturing a more diverse clientele.

The use of colour in a restaurant in the south of Madrid helps us to exemplify this point (Figure 2). Bright yellow and red cover several walls, decorated with light grey and beige tiles in their lower part. On one of our visits we asked the owner about the choice of colours, she replied that she was short of money and could not use a greater variety. 
As for the choice of the current colours, she explained that some years ago she took a course on how to enhance the customer experience at restaurants, and colours played an important role in it: 'In that course I was told that clients feel like eating more when surrounded by colours like red, yellow. . . by strong colours.' So she and her family painted the restaurant mostly in yellow and red. Coincidentally or not, yellow and red feature in both the Spanish and the Ecuadorian flags. If we consider only colours and ignore shields and shapes, their only difference would be the dark blue featuring in the Ecuadorian flag. The owner of this restaurant also described how several customers had humorously asked if she was Ecuadorian or Spanish while pointing at the walls. 'They ask why the colour blue is absent, because we have only yellow and red. We should put some blue, we are painting soon', she quickly added as a sort of apology - despite the fact that she has been a citizen of both countries for more than a decade.

This seemingly trivial point is indicative of at least two issues. First, in this and many other restaurants, customers and owners are attuned to symbols of the national or regional. In this case, some customers noticed the absence of blue and interpreted it as an ambiguity in national affiliation, which illustrates how the materiality of these restaurants is loaded with meanings of belonging by both customers and owners. Second, it shows how material arrangements are used to construct meanings of Ecuadorianness and Spanishness as inherently distinct and different. This distinction, of course, is based on certain essentialisation of what 'Ecuadorian' or 'Spanish' mean. These meanings, however, are materialised in the restaurant through forms of hybridity that are more or less evident in the objects and decoration of the restaurants. Contrasting with the identitarian strategy described above, liminal restaurants feature an ambiguity that sways between the migrant-origin restaurant, the mainstream Spanish restaurant and the working-class restaurant broadly conceived. These places call for some social mimicry in their efforts to capture a wider clientele. They are liminal in the sense of seeking a position in the thresholds between Pan-Latin American, Ecuadorian and Spanish restaurants. 'We've got a bit of everything', highlights the owner when referring to either her dishes or her clientele.

This is a pragmatic arrangement seeking to attract clients from the local community with a cheap and reliable menu, rather than targeting 'real Ecuadorians' by putting belonging upfront. Going liminal may be a matter of survival, wherever a clientele coming from a single country does not suffice and mainstream low-cost restaurants are the real competitors. A more or less nostalgic Ecuadorian client would no doubt distinguish the national dishes consumed here. Yet, this restaurant caters also to non-Ecuadorians which is why the identitarian trait is downplayed or hybridised with different references, including Spanish ones.

\section{Touristic: Ecuador as a Product}

Yet another mode of employing Ecuadorianness is a touristic tactic. These are places that seem to be selling something more than food, catering to a range of clients that need not overlap with Ecuadorians or Latin Americans only. Contrasting with the identitarian and liminal ones, these restaurants use clean and embellished pictures of tourist places from throughout Ecuador. They complement the distinctive traits of Ecuadorian cuisine with 


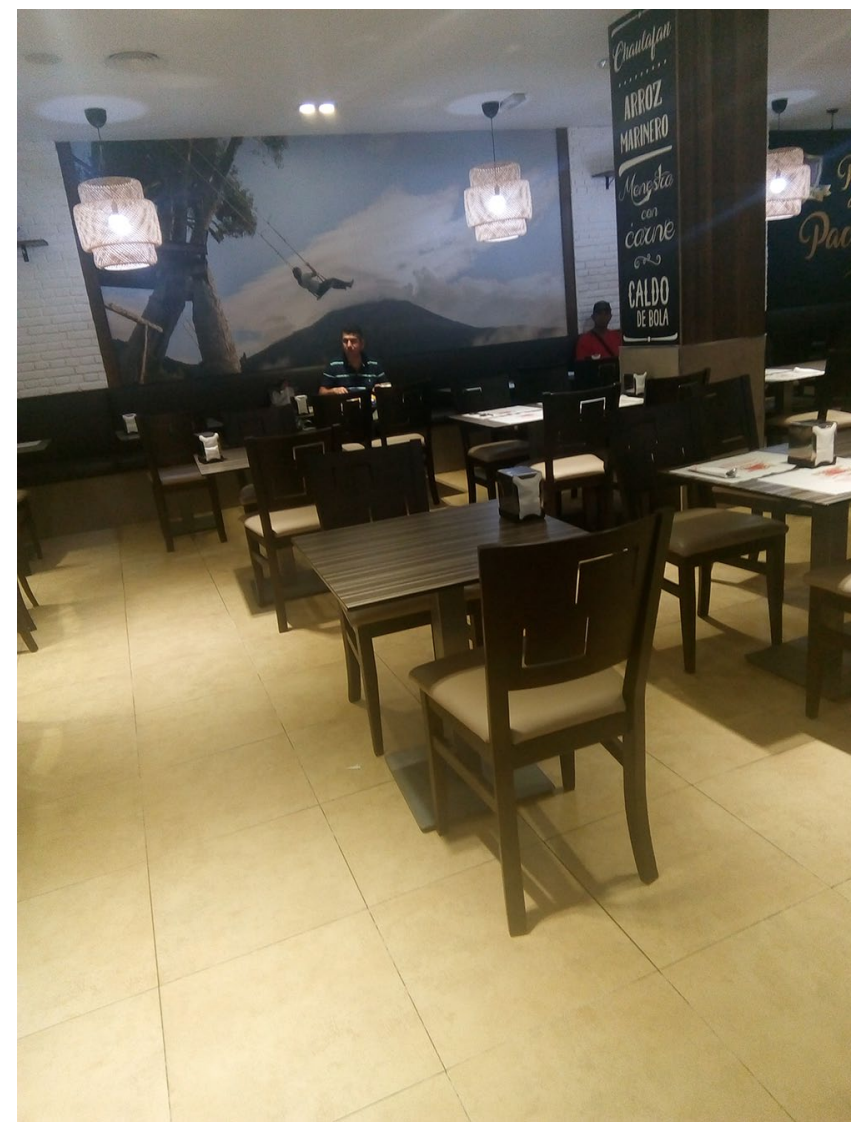

Figure 3. Touristic restaurant.

that of the lived environments in which the food was originally produced and consumed. An example comes from a chain of restaurants with large, clean and well lit spaces. One of its branches is a ventilated and air conditioned place in which the food smells are barely noticeable (Figure 3). The kitchen, hidden from the customer's view, is continuously open throughout the day. As a neat-uniformed waiter mentioned, 'here you can have a good meal late in the afternoon or early in the evening if you want'. In this restaurant Ecuador is produced as a touristic destination, and Ecuadorianness as a form of gastronomic vacation. Large pictures or skylines of Quito, Cuenca or Guayaquil are oriented to sell the restaurant brand, rather than the beauty of that country. The large logo is displayed on each wall, as big as large pictures of a lagoon with some huts in the Amazon, or vintage pictures of national monuments. Paper placemats show the logo in the middle and, on each side, there is the Ecuadorian national shield and the Spanish flag.

References to national or ethnic belonging may be present here and there, but the brand always comes first, marketised as professional, efficient and clean. Likewise, the backbar is neat and shining, with a number of wine and spirit bottles on display. Yet, at a 
closer gaze, a small trace of biographical personalisation can be discovered even here. There is a small portrait of Jesus Christ, youngish and almost immaculate, half-hidden behind the microwave oven, close to a sugar box. As in the previous examples, 'Ecuadorian' is used as an adjective, but the ways of representing that country - and consequently its meaning as a home-place - are remarkably distinct. At first sight, there is not much of a surprise in a touristic variation of 'Ecuadorian' as a brand. Yet, this is by no means obvious for a label, such as the Ecuadorian, with little of the fashionable traits associated with other international cuisines, such as the Peruvian cuisine currently in vogue (Lauer and Lauer, 2006).

\section{Distinctive: Ecuador as an Asset}

Still less obvious, and far more selective and incipient, there is another mode of producing and diffusing Ecuadorianness among restaurants in Madrid. At these distinctive restaurants, very few to our knowledge, 'Ecuadorian' is less a source of nostalgia, allegiance or exotic fascination than an embodiment of cultural capital in its own right. Against the predominant views of Ecuador as a poor place, and of Ecuadorians as low-skilled manual workers at best, these restaurants display works of art, literature and poetry that bear witness to the original contribution of Ecuadorian culture(s). Having a middle-class and culturally diverse client target, these places reframe Ecuadorianness as a positive legacy to share with the world, rather than a loss or something to be fictitiously recreated anew.

In one of the distinctive restaurants where we spent most of the time, the audio speakers play selected Ecuadorian tunes, old and new, contrasting with other restaurants playing the Latino hits or simply having the TV on. Low lights, wooden furniture and works of art furnish the place, creating an air of warmth and comfort (Figure 4). The tables are set with wine glasses and a selection of bottled beers are served in special glasses. The menu is diverse, featuring original dishes that are cooked a la ecuatoriana but draw inspiration from other cuisines, such as French, Mexican or Peruvian. The chef and owner of this restaurant comes from a city in the Ecuadorian Andes and grew up in his mother's restaurant, learning the rudiments of the typical cuisine from the Sierra. He moved to Spain in his adulthood, worked in the construction industry for a brief period and then shifted to hospitality. For several years he washed dishes and worked as a waiter while studying gastronomy.

In setting up his restaurant from scratch, he sought to go against the stigmatised meanings around Ecuadorianness in Madrid. 'If I had decorated the place with flags', he mentioned, 'this place could have been categorised as an eatery in which people speak loud and get drunk'. This strategy is also based on his personal understanding of the clientele, which he categorises in relation to their cultural and economic capital (Bourdieu, 1986). 'There are two types of Ecuadorian customers', the chef mentioned, 'the ones who appreciate good food and don't mind spending a couple of Euros more, and those who want to have the cheapest possible filling meal'. And what may seem as a quest for antistigma and the cultivation of culinary taste (Capellini et al., 2015) appears also to be a manifestation of a broader and more complex issue: the search for forms of belonging that seek to reshape stereotypes under circumstances of migration. This is why this chef puts so much emphasis on the need to develop technical skills and professionalism 


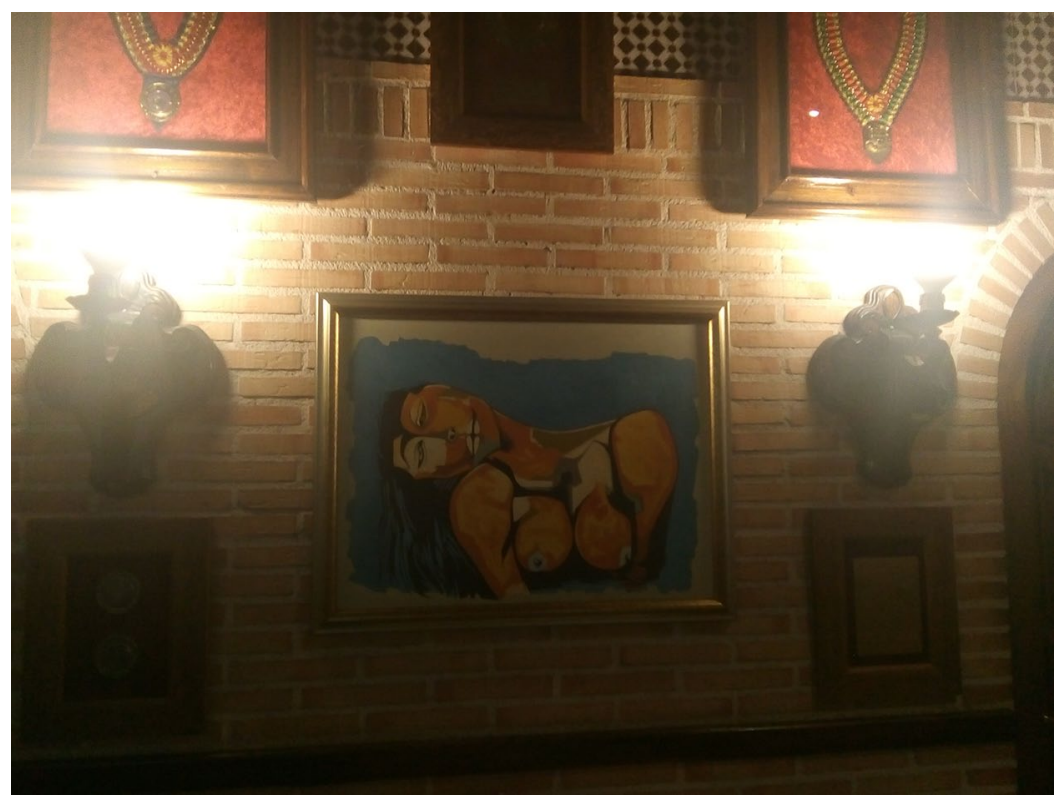

Figure 4. Distinctive restaurant.

among fellow restauranteurs. Fusing and innovating, rather than seeking authenticity (Scarpato and Daniele, 2003), are at the core of his daily menu: 'Some people tell me "what you do is not Ecuadorian food", but I tell them that this is Ecuadorian food that they have never tasted before!'

\section{Across Categories: Restaurant Tactics as Material and Culinary Translations}

With specific audiences in mind, the owners and workers in these restaurants seek to translate meanings of Ecuadorianness through specific material arrangements. They constitute more or less essentialised notions of belonging to a nationality that may resonate with what some customers assume to be Ecuadorian. The identitarian, liminal, touristic and distinctive tactics in these restaurants are forms of material and 'culinary translations' (Sammells, 2016), as they attempt to facilitate the mnemonic and sensorial recreation of a sense of familiarity and home.

So far, this section has described the main aesthetic and functional materials that can be noticed and associated with different ideal-typical settings in Ecuadorian restaurants. However, the use of the material culture at these restaurants is crucial to facilitate a sense of familiarity, or even a sense of home. There are various activities aimed to domesticate the space through the use of particular artefacts, no less than by the diffusion of smells, colours and tastes. How is that familiarity made possible in practice? What is there to be perceived, portrayed, enacted or assumed as distinctly Ecuadorian? And with what registers are the material arrangements in these settings playing? 


\section{Instances of Domestication: The Uses of Makeshift Living Rooms, Skilful Eating and Backbars}

The production of a sense of home in these restaurants involves, as we suggested above, some 'domestication of space'. This domestication does not amount only to the representations of national or ethnic belonging directed to a predominantly immigrant clientele. It also refers to the ways in which activities regularly associated with privacy and domestic spaces are enacted in a semi-public setting. These actions, as Kumar and Makarova (2008: 325) maintain, tend to 'remain intensely private, even intimate'. In this section we focus on the uses of different parts of the restaurants as instances of domestication. These activities constitute forms of personalisation in which the manipulation and display of artefacts, and the development of relationships between materials and individuals meet the public eye. An instance comes from the way in which people running these restaurants transform them into home-like spaces through material arrangements and mundane routines.

One afternoon we entered an identitarian restaurant located in a minor street in east Madrid. Three people, who happened to be the owners that run this family business, were having a late lunch at a moment of the day in which there were no customers. We apologised for interrupting them and ordered just a drink while they were finishing their lunch. We joined them some tables away while staring at the large TV screen with a broadcasting of an old American western movie dubbed in Spanish. As one of us walked to the end of the restaurant searching for the toilet, a woman suddenly stood up, giving precise directions about the location of the restrooms with an air of discomfort, as if that was an intrusion of a private space. Our presence there felt like something out of place, no matter how formally 'open' the place was. We realised that the degrees of privacy or publicness in the different areas of these restaurants often depend on the moment of the day. When there are no clients around, people running these restaurants turn these spaces into environments that lean towards the private. As the majority of these family businesses operate as all-day service, a significant part of their family life is conducted there. Some corners of these restaurants have an air of living room, of domestic space. In another liminal restaurant an owner explained that she would prefer to be closer to the city centre, but ended up choosing that location because the rent was affordable and it was close to her daughters' school and their house. She finally set up the restaurant in a neighbourhood that allows her to have a family life while running her business. They spend most of the day in the restaurant. The girls do their homework on one of the tables and sometimes help running errands. A table and the chairs most proximate to the kitchen, which happen to be in front of the large TV screen, serve as replacement of their sofa. The girls were excitedly discussing Ironman (the movie) with their parents in an afternoon in which one of us was the only client. This sense of domesticity, familiarity and belonging is not produced with the customers in mind. It rather emerges from the recurrent engagement with activities that most people tend to do in private. While enacted in the publicness of the restaurant, these activities still carry much of their intimate character.

There are also instances of domestication of space among the customers that operate as embodied experiences. Some clients keep on coming to these places because it feels comforting, nourishing and close. This production of familiarity through food requires 
an aptitude and certain know-how. The effortlessly and precise way in which certain customers manipulate the dishes relies on gestures that have become ingrained through repetition and the passage of time: the way they squeeze a lime or add some spicy sauce while swirling and cooling their soup, for instance. These embodied dispositions are essential for drawing comfort from the dishes that one identifies with previous life stages. In other words, producing a sense of home through food requires long-term exposure to specific ways of eating and sharing meals with others. While most people could draw pleasure from a given dish regardless of their acquaintance with it, producing familiarity through the consumption of specific food requires a set of bodily dispositions. This experience is what Hage (2014: 151), recalling Spinoza and Bourdieu, refers to as an 'ability to deploy oneself efficiently in the world'. It might be that the dishes customers have in these Ecuadorian restaurants are not ideally cooked, as we occasionally heard complaints from people questioning their genuineness or quality. Distance and the passage of time are key ingredients for idealising food. Yet, many customers return because the sense of familiarity produced in these restaurants is also a faculty, an aptitude that they have; a skill for bringing memory into the present.

Yet another instance of domestication takes place in certain corners of these restaurants through decorations that articulate and cultivate private concerns. The most telling example we found is the backbar. The vast majority of restaurants in Madrid have a countertop bar regardless of having or not a national affiliation. This is so because they are eateries just as much as spaces for casual socialisation in which to have a drink. All of the Ecuadorian restaurants we visited had a bar, either because these rented spaces already had one, or out of mere tradition. And while the appearance of the countertop bars in most restaurants in Madrid is similar, the backbar in Ecuadorian restaurants - the space behind the countertop - is a repository of assorted artefacts that turns this corner into a personalised area. The backbar does not obey the logic of evoking Ecuador in conspicuous and stereotypical ways. This is a niche which blends the domestic and semi-public, and also distinguishes the Ecuadorian restaurants from their mainstream counterparts.

'I'm Ecuadorian, but I didn't want to put much Ecuadorian decoration', says the owner of a liminal restaurant. Indeed, her restaurant does not attempt to highlight 'Ecuadorianness', but to offer a range of dishes in an atmosphere that overlaps the Ecuadorian decoration with Spanish and Pan-South American. The backbar, however, tells a different story (Figure 5). Backed by large mirrors, the largest shelves feature an assortment of liquors while two smaller shelves hold a couple of dolls, a glass tankard that holds pens and has the logo of a local beer, a small and carefully decorated figure of a virgin, a glass with a candle inside, a polaroid photo of a baby, small wooden elephants, a scale figure of a horse made in onyx, a ceramic figure of an owl and a small-scale supermarket trolley holding a miniature bottle inside. In this and other restaurants, what people display in the backbar may appear to fall into religious, regional or national lines. But these assortments of objects do not obey such logic. When we asked the owners about the meaning and origin of the objects placed there, they were hesitant and ambiguous. Certain objects, of course, have specifically to do with their biographies, private lives or religious beliefs. Yet, there is no sharp explanation as to why certain items are placed there. The backbar of the Ecuadorian restaurants in Madrid is not an issue of 


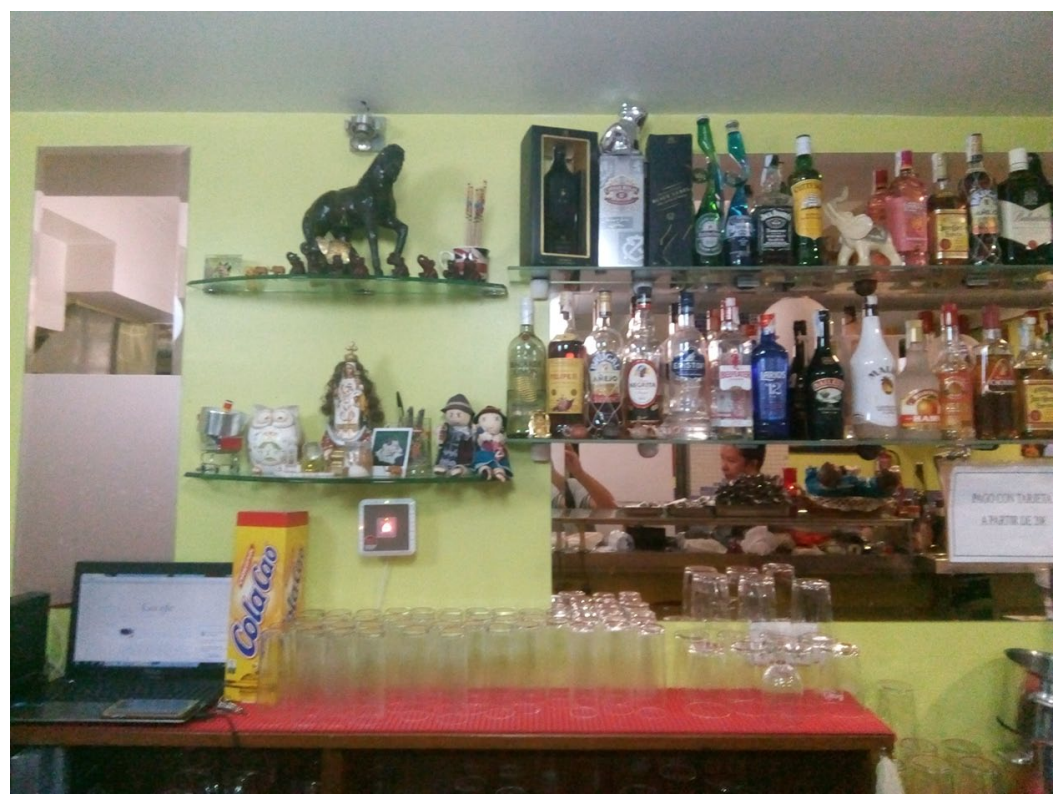

Figure 5. Backbar.

displaying some objects instead of others to represent or evoke specific meanings. Rather, it is a messy and very personal display of paraphernalia.

For the owners of the restaurants, the backbar is also a space for the memorable: a black and red rooster from a trip to Portugal, handmade dolls from Otavalo in Ecuador, souvenir plates depicting the arc de triomphe or Montmartre in Paris. The memorabilia cornered among bottles of spirits relates in subtle ways the personal with the public. It is an interface, a mediator. And far from being a matter of taste or status, these souvenirs hold the potential to create a familiar environment. The functional facet of the backbar consists in displaying diverse spirits to the clientele. It also arranges the bottles within an easy reach to the person serving those drinks. But in Ecuadorian restaurants, it consistently goes beyond this logic of functionality. Contrasting with other areas, this corner is only accessible to people working in the restaurant while being visible to customers. It is a sort of intimate space that others can see but not reach. In here the personal meets the public eye, turning this corner into a performance of domesticity in the semi-public. This use of the backbar is, therefore, an instance of domestication - a 'cultivation' of intimate relationships between people, artefacts and environments (Ingold, 2000).

There are some differences among restaurants, even in this respect: a distinctive one features paintings along with dolls wearing traditional costumes, while an identitarian may feature flags or handcrafted souvenirs from Ecuador. But this area is far less consistent and coherent than the material arrangements in the rest of the restaurants, escaping the logic of decoration or marketisation. A chain of touristic restaurants may generally look standardised, tidy and clean, but their backbars still show personalised items: a religious figure, a decorative scaled motorcycle holding a bottle of red wine on its top, a 
plastic figure of the Joker holding candies. At least in this special place, then, a restaurant says less of Ecuador, or the ways of representing it, than of the biographies of those who manage it. Put differently, the backbar works out as a source of domestication at a still different level: not only in evoking a more or less essentialised group identity as Ecuadorian (the 'collective home' of the past), but also in foregrounding something of the identities and histories of the managers - in a way, their 'family homes', which need not be articulated only, or even primarily, as a matter of Ecuadorianness.

This is a form of familiarity that lacks the coherence sought in cultural taste: instead of discerning what is 'good' or 'typical', this paraphernalia can feature a Catholic virgin beside a frame showing an alcohol licence from the local council, bottles of whiskey and a llama made of felt. The backbar is an area that produces familiarity to those who work there, expressing an ambiguity to the public in unuttered ways. This is why this area and more generally, the material culture in these restaurants - is not merely a nostalgic environment in which to search for ontological security. It is, as Pickering and Keightley (2006: 921) put it in their discussion of nostalgia, 'a means of taking one's bearings of the road ahead in the uncertainties of the present'. In personalising their backbars, owners or workers do a job of cultural translation that articulates what different forms of belonging (e.g. national, regional or religious ones) mean to them. As Benjamin (2007: 75) wrote, 'all translation is only a somewhat provisional way of coming to terms with the foreignness of languages'. As a form of translation, placing and arranging objects in the backbar is a provisional way of coming to terms with the tension between the private and familiar enacted in a semi-public and foreign environment. In essence, the backbar is a way of communicating domesticity amid foreignness.

\section{Conclusion}

The material culture of restaurants can be used to produce different senses of home and familiarity. Based on the analysis of several Ecuadorian restaurants in Madrid, this article revisited the relationship between the material arrangements and the ways of enacting national and ethnic forms of belonging. More specifically, we have moved from material culture as a static reproduction of pre-existing identities (such as Ecuadorian), to material culture as the ongoing enactment of domesticity and a sense of familiarity in a foreign environment.

Investigating Ecuadorian restaurants in Madrid has gradually enabled us to make better sense of, and do more justice to, the forms of domestication enacted in these places. Experiencing a sense of familiarity and home in a migrant-origin restaurant is not just a product of the ways in which it labels itself as Ecuadorian, arranges its material culture accordingly, or evokes a sense of home(land) to a mostly immigrant clientele. Also important, and less obvious, is the process of domestication mediated by embedded routines that emit a sense of ordinariness, security, even identification, to different audiences. This calls, analytically speaking, for a dual transition: from national belonging as a blurred, but evocative collective category ('Ecuadorianness'), to the ways of producing, evoking and claiming it in practice; from a sense of home that can be elicited by particular material arrangements along national, ethnic or religious lines of identification, to the fine-grained and sensuous ways of cultivating familiarity that are enabled by the materiality of a 
particular place. These situated forms in which the domestic 'drips' onto the semi-public are critical indicators of the achievement of familiarity - we could say, of home in the public - as an embodied, interactive and affective process. From a sociological optic, this micro-level research has proved valuable to illuminate broader questions concerning the hybridising and boundary-making between public and private (Sheller and Urry, 2003), between the values and habits of the homeland and of the hostland, and even between the legacy of the past and the pressures and opportunities of the present.

As we observed in the backbar, bringing the private into the public creates instances of familiarity and a sense of home at a very personal level, rather than a national or ethnic one. Interestingly, these corners lack the internal consistency that it is possible to observe in the decorations of the restaurant. The private 'dripping' onto the public is messy, producing its own logic. It reflects personal tastes, values and maybe contingent whims, rather than a consistent pattern of presentation of the (individual or family) self. Nonetheless, it points to a promising way ahead for investigating migrants' personal histories and their continuous balancing acts between foreign and mainstream, no less than between private and public. A significant aspect of migrant-origin restaurants that would still benefit from systematic and comparative research has precisely to do with the thresholding and displaying functions of the backbars.

Overall, these shifts open a novel space for research on the ways in which people, including migrants and ethnic minorities, make themselves at home in a semi-public environment. Material culture matters, for this purpose, not only for its power to evoke abstract forms of identification, allegiance or nostalgia, such as those we call Ecuadorianness. As fundamental are the sensuous and embodied ways in which these restaurants convey through food a range of positive emotions that the word home may capture: comfort, continuity of the past and freedom to articulate one's own tastes. It is in all of these respects, regardless of migrant background, that consuming (good) food turns out to be so critical - and surprisingly understudied - for all of us to make ourselves at home.

\section{Funding}

The authors disclosed receipt of the following financial support for the research, authorship and/or publication of this article: this research was funded by the European Research Council (ERC) under the EU Horizon 2020 research and innovation programme (grant no. 678456).

\section{ORCID iD}

Alejandro Miranda-Nieto (iD https://orcid.org/0000-0003-4630-4379

\section{Note}

1. As of July 2018, Ecuadorians are the largest community of foreign-born residents in Madrid, amounting to 12.5 per cent (source: Madrid Municipality, 'Población nacida fuera de España residente en la ciudad de Madrid', www.madrid.es).

\section{References}

Abbots EJ (2016) Approaches to food and migration. In: Klein J and Watson J (eds) The Handbook of Food and Anthropology. London: Bloomsbury. 
Ayuntamiento de Madrid (2018) Censo de locales, sus actividades y terrazas de hostelería y restauración. Available at: datos.madrid.es.

Bailey A (2017) The migrant suitcase: Food, belonging and commensality among Indian migrants in the Netherlands. Appetite 110: 51-60.

Benjamin W (2007) Illuminations: Reflections and Essays. New York: Shocken Books.

Beriss D and Sutton D (2007) The Restaurants Book. New York: Berg.

Blunt A and Dowling R (2007) Home. London: Routledge.

Blunt A and Sheringham O (2019) Home-city geographies. Progress in Human Geography 43(5): 815-834.

Boccagni P (2017) Migration and the Search for Home: Mapping Domestic Space in Migrants' Everyday Lives. New York: Palgrave.

Boccagni P and Duyvendak JW (2019) On the 'scaling up' of home in majority-minority relations: A conceptual inquiry and a research agenda. HOMInG Working Paper no. 6_2019.

Bourdieu P (1986) The forms of capital. In: Richardson JG (ed.) Handbook for Theory and Research for the Sociology of Education. New York: Greenwood.

Capellini B, Parsons E and Harman V (2015) 'Right taste, wrong place': Local food cultures, (dis)identification and the formation of classed identity. Sociology 50(6): 1089-1105.

Cebrián de Miguel JA, Jiménez Blasco BC and Resino García RM (2016) Inmigrantes emprendedores durante la crisis económica. Migraciones 40: 63-92.

Collins EL (2008) Of kimchi and coffee: Globalisation, transnationalism and familiarity in culinary consumption. Social and Cultural Geography 9: 151-169.

Córdoba J (2015) Una aproximación a la inmigración ecuatoriana en España (1995-2005). Iberoamérica Social 4: 73-83.

Easthope H (2004) A place called home. Housing, Theory and Society 21(3): 128-138.

Hage G (2014) Eavesdropping on Bourdieu's philosophers. In: Das V, Jackson M, Kleinman A, et al. (eds) The Ground Between. Durham: DUP, 138-158.

Herrera G and Torres A (2005) La Migración Ecuatoriana. Quito: FLACSO.

Hondagneu-Sotelo P (2017) At home in inner city: Immigrant community gardens. Journal of Housing and the Built Environment 32(1): 13-28.

Iglesias Martínez J, Moreno Márquez G, Fernández García M, et al. (2015) La población de origen ecuatoriano en España. Report, Embajada del Ecuador, Comillas, Ikuspegi.

Ingold T (2000) The Perception of the Environment. London: Routledge.

Jackson M (2017) How Lifeworlds Work: Emotionality, Sociality, and the Ambiguity of Being. Chicago, IL: University of Chicago Press.

Johnson M (2016) 'Nothing is sweet in my mouth': Food, identity, and religion in African Lisbon. Food and Foodways 24(3-4): 234-256.

Koch R and Latham A (2013) On the hard work of domesticating a public space. Urban Studies 50(1): 6-21.

Krogstad A (2004) From chop suey to sushi, champagne, and VIP lounges. Social Analysis 48(1): $196-217$.

Kumar K and Makarova E (2008) The portable home: The domestication of public space. Sociological Theory 26(4): 324-343.

Kusenbach M and Paulsen K (2013) Home: International Perspectives on Culture, Identity and Belonging. Frankfurt: Peter Lang.

Lauer M and Lauer V (2006) La Revolución Gastronómica Peruana. Lima: USMP.

Mata-Codesal D (2010) Eating abroad, remembering (at) home. Anthropology of Food 7: 6642.

Pickering M and Keightley E (2006) The modalities of nostalgia. Current Sociology 54(6): 919-941.

Pieterse JN (2003) Social capital and migration. Ethnicities 3(1): 5-34. 
Recaño J (2004a) Las migraciones internas de retorno en España durante la primera mitad de la década de los noventa. Papers de Demografía 243.

Recaño J (2004b) Migraciones internas y distribución espacial de la población española. In: Leal Maldonado J and Leguina J (eds) Informe sobre la Situación Demográfica en España. Madrid: Fundación Matorell.

Recaño J (2006) Los intercambios poblacionales entre las regiones españolas. In: Leal Maldonado J and Fernández Cordón JA (eds) Análisis Territorial de la Demografía Española. Madrid: Fundación Martorell.

Sabar G and Posner R (2013) Remembering the past and constructing the future over a communal plate. Food, Culture and Society 16(2): 197-222.

Sammells CA (2016) Frosted windows and compartmentalized intimacies: Forging relationships in a Bolivian restaurant in Madrid. Food and Foodways 24(3-4): 213-231.

Scarpato R and Daniele R (2003) New global cuisine. In: Hall CM, Sharples L, Mitchell R, et al. (eds) Food Tourism around the World. Oxford: Elsevier.

Sheller M and Urry J (2003) Mobile transformations of 'public' and 'private' life. Theory, Culture \& Society 20(3): 107-125.

Sutton DE (2001) Remembrance of Repasts: An Anthropology of Food and Memory. Oxford: Berg. Warde A (2000) Eating globally: Cultural flows and the spread of ethnic restaurants. In: Kalb D, Van der Land M, Staring R, et al. (eds) The Ends of Globalization. New York: Roman \& Littlefield.

Warde A, Martens L and Olsen W (1999) Consumption and the problem of variety: Cultural omnivorousness, social distinction and dining out. Sociology 33(1): 105-127.

Warin M and Dennis S (2005) Threads of memory. Journal of Intercultural Studies 26(1-2): $159-170$.

Wessendorf S and Phillimore J (2018) New migrants' social integration, embedding and emplacement in superdiverse contexts. Sociology 53(1): 123-138.

Zambonelli V (2013) Brazilian restaurants and the transcultural making of place in Tokyo, Japan. In: Hou J (ed.) Transcultural Cities. London: Routledge.

\begin{abstract}
Alejandro Miranda-Nieto is a Postdoctoral Fellow at the Department of Sociology and Social Research at the University of Trento. His research focuses on the relationship between practices and various forms of mobility, dwelling, migration and social change. He is the author of academic articles on mobilities, migration, musical practice and ethnography. His book Musical Mobilities has been recently published in the Routledge Advances in Ethnography series.
\end{abstract}

Paolo Boccagni is a Professor at the Department of Sociology and Social Research at the University of Trento. His main research areas are transnational migration, social welfare, care, diversity and home. His publication record includes articles in Ethnic and Racial Studies, Global Networks, Journal of Ethnic and Migration Studies, and Housing, Theory and Society. His book Migration and the Search for Home has been published in the Palgrave Mobility and Politics series. He is principal investigator of the European Research Council project HOMInG - The home-migration nexus (2016-2021).

Date submitted January 2019

Date accepted February 2020 